\title{
Erratum: Effectiveness and Safety of Apixaban versus Warfarin as Outpatient Treatment of Venous Thromboembolism in U.S. Clinical Practice
}

Derek Weycker ${ }^{1}$ Xiaoyan Li $^{2}$ Gail DeVecchis Wygant ${ }^{2}$ Theodore Lee ${ }^{3}$ Melissa Hamilton ${ }^{2}$ Xuemei Luo ${ }^{4}$ Lien Vo ${ }^{2}$ Jack Mardekian ${ }^{3} \quad$ Xianying Pan ${ }^{5} \quad$ Leah Burns $^{2} \quad$ Mark Atwood $^{1}$ Ahuva Hanau ${ }^{1}$ Alexander T. Cohen ${ }^{6}$

1 Policy Analysis Inc. (PAI), Brookline, Massachusetts, United States

2 Bristol-Myers Squibb, Lawrenceville, New Jersey, United States

3 Pfizer Inc., New York, New York, United States

4 Pfizer Inc., Groton, Connecticut, United States

${ }^{5}$ Bristol-Myers Squibb, Wallingford, Connecticut, United States

${ }^{6}$ Guy's and St. Thomas' Hospitals, London, United Kingdom
Address for correspondence Derek Weycker, PhD, Policy Analysis Inc. (PAI), Four Davis Court, Brookline, Massachusetts, 02445, United States (e-mail: dweycker@pai2.com).

Thromb Haemost 2018;118:e1-e2.

ERRATUM
The authors have brought to the publisher's attention that there were some errors in - Fig. 1 of the article and $\boldsymbol{-}$ Table 1 of the Supplementary Material published in the above article in Thrombosis and Haemostasis, Volume 118, Number 8, 2018 (DOI: 1 10.1055/s-0038-1673689). The corrected figure and table appear as follows:
DOI https://doi.org/ $10.1055 / \mathrm{s}-0039-3400530$. ISSN 0340-6245.
(C) 2020. The Author(s).

This is an open access article published by Thieme under the terms of the Creative Commons Attribution-NonDerivative-NonCommercial-License, permitting copying and reproduction so long as the original work is given appropriate credit. Contents may not be used for commercial purposes, or adapted, remixed, transformed or built upon. (https://creativecommons.org/ licenses/by-nc-nd/4.0/)

Georg Thieme Verlag KG, Rüdigerstraße 14, 70469 Stuttgart, Germany 


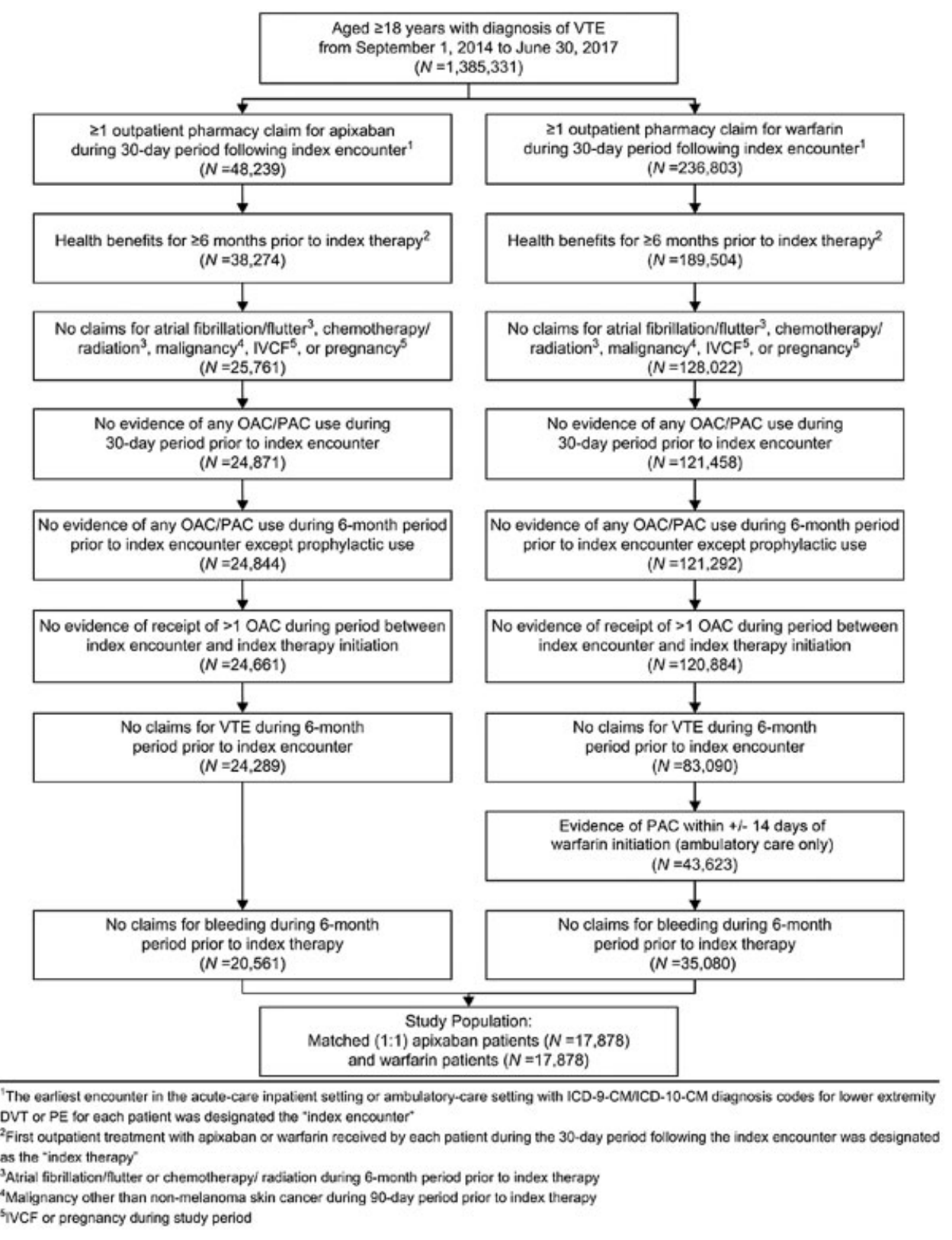

Fig. 1 Selection of patients receiving apixaban or warfarin as outpatient therapy for VTE. IVCF, inferior vena cava filter; OAC, oral anticoagulant; PAC, parenteral anticoagulant; VTE, venous thromboembolism. 